\title{
A SOBERANIA DO DISCURSO EM GÓRGIAS: PERSUASÃo E ENGANO
}

\author{
Cesar Augusto Mathias de Alencar ${ }^{1}$ \\ Universidade Federal do Amapá (UNIFAP) \\ https://orcid.org/0000-0003-3145-0584 \\ E-mail: dealencar.prof@gmail.com \\ Vinicius Brito Barros ${ }^{2}$ \\ Universidade Federal do Amapá (UNIFAP) \\ https://orcid.org/0000-0002-1143-0220 \\ E-mail: vbritobarros@gmail.com
}

\section{RESUMO:}

Lógos é termo grego central para a construção do movimento sofístico. Górgias de Leontinos, um dos principais representantes da primeira geração desse movimento, propôs-se a refletir, em Elogio de Helena, sobre o discurso como um grande e soberano senhor, capaz de ao mesmo tempo produzir persuasão em Helena e denunciar esse poder persuasivo. Na primeira parte deste estudo, pretendemos situar o lógos como fabricador de vivências em seu ouvinte, o que sugere a compreensão do poder persuasivo. Na segunda parte, a fabricação de vivências, diferente da persuasão, se identificará com uma realidade fictícia produzida devido ao engano voluntário. Por ser voluntária essa experiência do engano, o motivo da soberania do lógos está para Górgias, em que o discurso, além de persuadir, pode servir como instrumento possível para a fabricação de aprendizados, cuja experiência artística o seu próprio texto exemplifica.

PALAVRAS-CHAVE: Górgias; Discurso; Engano; Educação.

\section{THE SOVEREIGNTY OF DISCOURSE IN GORGIAS: PERSUASION AND ILLUSION}

\begin{abstract}
:
Logos is a central Greek term for the construction of the sophistic movement. Gorgias de Leontinos, one of the main representatives of the first generation of this movement, proposed to reflect, in Elogio de Helena, about the discourse as a great and sober master, able to produce persuasion in Helena and denouncing this persuasive power at the same time. In the first part of this study, we intend to situate logos as a producer of experiences in its listener, which is important in understanding the persuasive power. In the second part, the fabrication of experiences, different from persuasion, is identified with a fictitious reality produced due to voluntary deception. Because this experience of deception is voluntary, the reason for the sovereignty of logos is for Gorgias, in which speech, in addition to persuading, can serve as a possible instrument for the fabrication of learning, whose artistic experience his own text exemplifies.
\end{abstract}

KEYWORDS: Gorgias; Discourse; Illusion; Education.

\footnotetext{
${ }_{1}$ Doutor(a) em Filosofia pela Universidade Federal do Rio de Janeiro (UFRJ), Rio de Janeiro - RJ, Brasil. Professor(a) da Universidade Federal do Amapá (UNIFAP), Macapá - AP, Brasil.

${ }^{2}$ Graduando(a) em Filosofia na Universidade Federal do Amapá (UNIFAP), Macapá - AP, Brasil.
}

BARROS, Vinicius Brito.; ALENCAR, Cesar Augusto Mathias de. A soberania do discurso em Górgias: Persuasão e Engano. Griot : Revista de Filosofia, Amargosa - BA, v.21 n.3, p.248-257, outubro, 2021. 


\section{Introdução}

A linguagem é um dos fenômenos mais intrigantes da condição humana. Nesse sentido, é de se esperar que, desde a antiguidade, esse fenômeno fosse estudado com interesse e aplicação. Do tipo de reflexão surgida em território heleno, a linguagem muitas vezes circunscreveu preocupações em face da relação entre mýthos e lógos, sobretudo no que diz respeito ao nascimento da Filosofia. O que geralmente não se assume de modo claro é que as investigações filosóficas sobre a linguagem a partir de Sócrates encontram sua ascendência fundamental no movimento que assumiu a tarefa de estudar e ensinar o discurso como território de tudo o que diz respeito à condição humana: falamos da sofística grega.

Por volta do século V a.C., a Hélade presencia um movimento humanístico que modifica a perspectiva da tradição filosófica dos primeiros investigadores naturalistas, trazendo o enfoque de reflexão para o humano e a pólis. Pode-se dizer que a sofística é, essencialmente, um movimento paidêutico, ou seja, dedicado à educação, pois sua tarefa primordial é ensinar a areté (excelência ou virtude) sob a implicação do discurso (Cf. UNTERSTEINER, 2012). Majoritariamente estrangeiros, os sofistas vinham para Atenas em busca de bons pagadores para suas aulas. Górgias de Leontinos, por exemplo, costumava cobrar a vultosa soma de cem minas para ensinar (Cf. BARBOSA e CASTRO, 1993). O que permitia esse retorno estava no tipo de ensino proposto, afeito às demandas discursivas que o regime democrático provoca, valendo-se da linguagem e do lógos como ponto de concentração das habilidades a serem obtidas pelo virtuoso.

Para a demonstração da importância da linguagem no projeto sofístico de ensino, o Elogio de Helena é peça chave. Trata-se de um discurso epidíctico, aquele gênero de elogio público, de que Górgias foi um dos principais fundadores, cuja característica está em remodelar a prosa utilizando elementos até então próprios ao discurso poético (REBOUL, 2004). Sobretudo em vista desse Elogio, Górgias apresentou-se como um dos primeiros a compor a técnica do discurso que Platão depois iria nomear de Retórica ${ }^{3}$. A estruturação do seu Elogio, pretendendo renovar certa polêmica literária acerca da reputação da bela Helena, aquela personagem mítica a quem atribuíam responsabilidade pela guerra de Tróia (Cf. BARBOSA e CASTRO, 1993; DINUCCI, 2017), expõe-se como o jogo necessário do aprendizado - de maneira que é possível dizer, veremos, que sua tese sobre a força soberana e inescapável do lógos aponta para a técnica discursiva como fundamento do processo paidêutico.

No texto de Górgias, a defesa de Helena é feita pelos seguintes argumentos apresentados: $1^{\circ}$ a divindade quis que Helena fosse raptada; $2^{\circ}$ Páris levou Helena à força; $3^{\circ} \mathrm{O}$ lógos foi quem levou Helena; $4^{\circ}$ Éros dominou Helena, fazendo-a seguir com Páris. Independente do motivo, Helena não teve a possibilidade de decidir autonomamente, pois estava diante de forças superiores. No que se refere ao interesse desta investigação, o argumento 3 deixa claro, ainda que

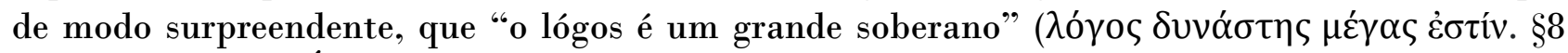
Elogio de Helena). É preciso indagar, afinal, por que o lógos deve ser considerado grande soberano? A que Górgias se refere com a ideia de um poder do discurso? De que maneira, em suma, essa analogia política põe em questão a natureza das relações humanas construídas no (através do) discurso?

Pretendemos indicar como possível uma resposta orientada por duas acepções. A primeira, diz respeito à natureza do lógos como capaz de fabricar experiências e vivências durante o processo

\footnotetext{
${ }_{3}^{3}$ Sobre a análise da Retórica como essencialmente fundada no gênero epidíctico, ver PERELMAN, 2004, p. 57-91. É no Górgias que Platão apresenta, pela primeira vez, a cunhagem da técnica retórica como atribuída ao sofista. Ver sobre isso SCHIAPPA (1990).
}

BARROS, Vinicius Brito.; ALENCAR, Cesar Augusto Mathias de. A soberania do discurso em Górgias: Persuasão e Engano. Griot : Revista de Filosofia, Amargosa - BA, v.21 n.3, p.248-257, outubro, 2021. 
de comunicação, porque o discurso não comunica coisas, e sim discurso sobre coisas. Se é por meio das palavras que os indivíduos se comunicam, os termos que compõem a discursividade jogam com a dinâmica imaginativa dos seus ouvintes, e é exatamente isso que, para Górgias, elas comunicam. O discurso sobre coisas, dessa forma, fabrica estados internos ao ouvinte que são construídos desde os estímulos daquele que se pronuncia. Em outras palavras, o poder soberano de autonomia do discurso está em ser possível aprender a partir de vivências sugeridas desde um outro, mas que se fazem experiência própria ao serem vivenciadas pela dinâmica discursiva. A natureza do lógos se esboça, com isso, por uma relação sedutora de sugestão e de empatia.

No entanto, não são todos os que se dispõem ou se mostram passíveis de ser afetados pelas sugestões do discurso. Há certa notícia que nos conta ter Górgias sido incapaz de enganar os tessálios. Questionado sobre a razão disso, o sofista teria respondido por serem "desprovidos de sensibilidade" (Plutarco, De Audiendis Poetis, 15c apud UNTERSTEINER, 2012, p. 182). Estamos aqui em face de um limite ao poder sugestivo do lógos, que de certo modo nos sugere talvez haver resistência à soberania do discurso. Essa indicação biográfica nos convida a refletir sobre o que parece ser uma distinção gorgiana entre persuasão (peithó) e engano (apáte). Ou seja, é possível não experienciar o poder de sugestão do lógos ao não ser capaz de se pôr afetado imaginativamente. Se o engano, com isso, aparece como voluntário, a persuasão será entendida como forçosa e violenta. A qualidade da educação, veremos, dependerá de que o ouvinte se abra ao engano, evitando a persuasão. Se a analogia política conferia ao lógos uma soberania inescapável, voluntária ou involuntariamente, será em vista de sua aplicação educativa que a posição de se deixar enganar pelo discurso se faz mais sábia.

\section{As fabricações do logos}

O discurso é um grande e soberano senhor que, com um corpo pequeníssimo e invisibilíssimo, diviníssimas ações opera.

Górgias, Elogio de Helena, §8 (DINUCCI, 2017).

A palavra $\lambda o ́ \gamma o \varsigma$, derivada do verbo grego $\lambda \varepsilon ́ \gamma \omega$, tem múltiplas acepções. Sobre o termo $\lambda \varepsilon^{\prime} \gamma \omega$, o Dictionnaire Étymologique de Pierre Chantraine afirma que "o sentido original é "juntar, colher, escolher' [...]. $\Lambda \dot{\varepsilon} \gamma \omega$ significa às vezes 'enumerar' [...], 'dirimir as injustiças' [...], no sentido de 'falar, discursar'. [...] Assim surgiu o significado de "narrar, dizer"” (1999, p. 625. tradução nossa $)^{4}$. Valendo-se desses últimos significados apresentados, as três traduções do Elogio de Helena usadas como base para este artigo trabalham com o significado de 'discursar', 'dizer', 'narrar' a fim de ressaltarem aquela que geralmente se entende como a tradução comum do termo $\lambda$ ó por 'discurso' (Cf. BARBOSA e CASTRO, 1993; CASSIN, 2005; DINUCCI, 2017). É importante, contudo, ter presente que aquelas acepções do termo em grego, ao oferecerem úteis indicativos sobre sua aplicação, põem para nós a questão de como Górgias o aplicará concebendo certa particularidade. Isso justifica porque continuaremos a utilizar o termo em sua forma grega e, na medida em que pudermos dizer 'discurso', faz-se importante recordar esse conjunto significativo que a palavra grega ecoa.

Deve-se primeiro acrescentar que, de maneira geral, lógos é um "termo em que o grego liga, como se sabe, na maneira de relacionar as coisas entre si, o fato de pensar e o de falar" (CASSIN, 2005, p. 66). Essa maneira de relacionar, de reunir por assim dizer, duas atividades

\footnotetext{
4 “le sens originel est 'rassembler, cueillir, choisir' [...]. $\Lambda \varepsilon ́ \gamma \omega$ signifie parfois ‘énumérer' [...], 'débiter des injures' [...], au moyen de 'bavarder, discourir'. [...] Ainsi est né l'emploi au sens de 'raconter, dire'. (CHANTRAINE, 1999, p. 625).
} 
próprias ao âmbito da linguagem (pensamento e fala) indicam certa preocupação do sofista com a reflexão possível do lógos sobre si mesmo e seus efeitos. Especificamente com Górgias, explica Untersteiner, o logos

exprime tanto o conceito de "exposição", construída sobre uma trama de ideias, como o de "palavra", "pensamento", mas de modo que a unidade de um e outro seja dada pela ideia de "razão". Por isso, quando Górgias, no elogio a Helena, fala de lógos, quer se referir tanto à palavra que individualmente exprime um conceito, como a uma proposição logicamente construída. (UNTERSTEINER, 2012, p. 285).

Se a maneira do lógos aponta para a consideração do racional, segundo a explicação acima, o racional está inevitavelmente presente para Górgias seja ao narrar uma estória seja ao argumentar em favor de uma tese. Não por acaso, a arte da qual Platão força Górgias a se dizer mestre - a retórica - não desconsidera a natureza funcional dos discursos (o próprio Elogio trará indicações interessantes acerca de propostas diversas no uso dos discursos, desde os narrativos até os argumentativos), pôs se trata de considerar, fundamentalmente, sua atividade e eficácia (PLATÃO, Górgias, 450b). Górgias ainda evidencia uma particularidade do lógos em outro texto seu, chamado Tratado do Não-Ser ${ }^{5}$ :

(84) o [...] meio do qual informamos é a palavra, mas a palavra não é as coisas que subsistem e nem os seres; portanto, não comunicamos seres aos que nos cercam, mas palavra, que é diferente das coisas que subsistem. Então, assim como o visível não se torna audível e vice-versa, do mesmo modo o ser, já que subsiste externamente, não poderia tornar-se a nossa palavra. (Sexto Empírico, Tratado do Não-Ser; DINUCCI, 2017, p. 97 $98)^{6}$.

Quer dizer, o lógos difere das coisas que nomeia num ponto que, entre o âmbito das palavras e o das coisas, não pode haver assimilação possível. As coisas nomeadas não se tornam os discursos que as nomeiam, assim como os discursos que nomeiam as coisas não se tornam as coisas nomeadas. Ao reduzir ao absurdo a pretensão de Parmênides em firmar uma assimilação necessária entre pensar e ser, Górgias joga com a incomunicabilidade em razão exatamente do que a deusa se põe a comunicar pelas palavras do eleata: em outras palavras, se o elemento da comunicação entre falantes é somente o lógos, ou seja, o discurso sobre algo (logos peri tinos), e não algo em discurso (logos tinos), então o ser e o pensar, sendo o mesmo, são no lógos - e, com isso, a deusa ensina nada senão o próprio ato de dizer como capaz de fazer ser (cf. CASSIN, 2005, p. 34$43)$.

Em função disso, parece lícito corroborar Untersteiner (2012) ao reforçar a interpretação do lógos servir melhor como sugestionador do que como comunicador de coisas e de experiências. Essa posição é sustentada por Untersteiner porque

a palavra não significa para um e outro rigorosamente a mesma coisa, pois diferem um do outro por suas mentalidades, por suas culturas, pelos sentidos de sua língua [...] As palavras despertam em nós tanto mais impressões quanto mais a nossa consciência está

\footnotetext{
${ }^{5} \mathrm{O}$ Tratado do Não-Ser é um texto de Górgias de Leontinos que chegou até nosso tempo por meio de duas paráfrases em dois escritos diferentes. Através do De Melisso, Xenófanes e Górgias, atribuído a um autor anônimo com várias divergências sobre sua real identidade, e por meio de Contra os matemáticos (livro VII, 65-87) de Sexto Empírico, que viveu aproximadamente no séc. II d.C. A versão usada do Tratado do Não-Ser é a de Sexto Empírico, por mencionar o processo de formação da palavra. A tradução para esse propósito é a de DINUCCI (2017).

${ }^{6}$ Quando a referida tradução do Tratado do Não Ser utilizar o termo 'palavra', remeta-se ao termo 'discurso' enquanto tradução para 'lógos'
} 
carregada de conhecimentos, sentimentos, lembranças, e oferece um terreno mais bem preparado à sugestão. (Marouzeau, 1935, pp. 132-133 apud UNTERSTEINER, 2012, pp. 284-285).

Nesse sentido, como explica Salles (2014), sugestionar é equivalente a fabricar dinâmicas emocionais, mentais e intelectuais no ouvinte, sendo essas dinâmicas diferentes das que o ouvinte vivenciou antes de ouvir o discurso. Por esse motivo, Górgias indica como equivalentes o poder do lógos e o poder dos medicamentos. A analogia se estabelece da seguinte forma:

\begin{abstract}
a mesma relação tem o poder dos discursos com a boa ordem da alma, e o poder dos medicamentos com o estado natural dos corpos, pois, do mesmo modo que certos medicamentos expulsam do corpo certos humores (e uns suprimem a doença; outros, a vida), assim também, entre as palavras, umas afligem, outras encantam, outras amedrontam, outras estabelecem confiança nos ouvintes, outras ainda, através de sórdida persuasão, envenenam e enganam a alma. (Górgias, Elogio de Helena, §14; DINUCCI, 2017, pp. 71-72).
\end{abstract}

Se lembrarmos que a palavra em grego para medicamento, pharmakon, refere-se a veneno ou droga, a depender do contexto de aplicação (ver também CASSIN, 2005, p. 54), a analogia acima deixa patente a capacidade discursiva como capaz de fabricar certa dinâmicas no ouvinte, que mudarão sua disposição anímica tal como medicamentos fabricam dinâmicas que alteram a disposição constitutiva para um estado que não estava presente antes da sua ingestão. Nesse ponto, entendemos a crítica que Cassin faz à posição behaviorista da leitura de Mourelatos (cf. CASSIN, 2005, p. 55), porque o discurso, para Górgias, embora se produza no acontecer do estímulo que provoca, esse estímulo não substitui a realidade - mas a cria.

Se assim for, nada impede que uma das dinâmicas possíveis seja a fabricação de aprendizados naqueles que ouvem. Parece conveniente dizer isso porque nem todas as experiências comunicadas pelo lógos já foram vivenciadas pelos ouvintes. $O$ que não impossibilita o aprendizado a partir da experiência alheia. Um exemplo disso ocorre no próprio Elogio de Helena quando Górgias fabrica diante dos ouvintes a experiência de ser injustamente acusado e difamado por situações que estão fora do domínio de ação de alguém, como ocorreu com Helena. Diz Górgias: "Ao ter sido submetida à força, privada da pátria e afastada dos amigos, como não, com razão, ela antes inspiraria piedade que difamação?" (Elogio de Helena, §7; DINUCCI, 2017, p. 69).

Além do exemplo presente no Elogio de Helena, a fabricação de aprendizados por meio da experiência alheia, presente nas tragédias gregas, é uma das influências sobre o pensamento gorgiano. Por isso, cabe expor as relações que Salles (2014) estabeleceu entre a poesia trágica e a concepção discursiva de Górgias:

[...] talvez, a palavra poética, do modo como se refere a ela Górgias, possa também ser pensada como uma palavra que possui, de modo similar ao que propôs Aristóteles, uma dimensão catártica, considerando-se a capacidade da linguagem de fabricar vivências afetivas fundamentais, na experiência da alteridade que é provocada pela poesia. (SALLES, 2014, p. 87).

Em resumo, para Górgias, o lógos se realiza por narração e argumentação. Mais do que isso, o lógos comunica-se ele mesmo, ele basta-se em sua autonomia, visto que não se pode discursar sobre as coisas tais como elas são e nem transformar o discurso sobre as coisas na própria coisa sobre a qual se fala. Por esse motivo, o lógos estimula e sugestiona. Ou seja, fabrica experiências nos ouvintes e, desse modo, torna-se equivalente a um medicamento. Tanto quanto 
um medicamento fabrica uma dinâmica no corpo, o lógos fabrica dinâmicas anímicas nos ouvintes. Indicamos, por fim, como uma dessas dinâmicas de fabricação, o aprendizado afetivo a partir de experiências alheias. Isso nos leva a indagar de que maneira a soberania do lógos, dada sua autonomia, realiza seu poder na educação de um modo distinto ao que geralmente se expõe no âmbito da persuasão.

\section{O engano voluntário}

Para pensarmos certa condição educativa proposta por Górgias, será importante dizer que a particularidade do meio de fabricar aprendizados pelo lógos ocorre no fenômeno do engano

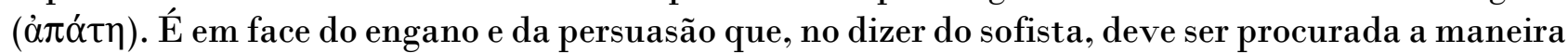
de livrar Helena da culpa a ela impingida, quanto ao argumento 3: "Se o discurso a persuadiu e sua alma enganou, não é difícil, quanto a isso, defendê-la e, assim, liberá-la da responsabilidade"

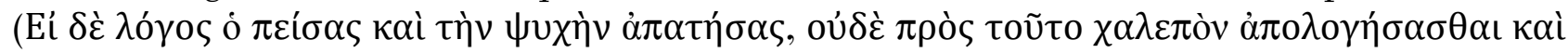

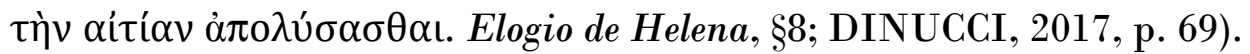

Destaca-se, desde logo, a presença de uma relação entre engano e alma, posta ao lado de uma relação entre lógos e persuasão. A tradução de Cassin pretendeu evidenciar o tipo de ligação que o engano parece possuir junto à alma do ouvinte: "Mas se aquele que a persuadiu, que construiu uma ilusão em sua alma, foi o discurso, também não será difícil defendê-la contra essa acusação [...]" (CASSIN, 2005, p. 296, grifo nosso). Como se pode ver, a partir dessas duas traduções do texto de Górgias, o engano é um tipo de fabricação que ilude, ou melhor dizendo, constrói uma realidade para o ouvinte e que, por ser uma fabricação, não se refere necessariamente a algo efetivamente real.

Qual o estatuto, porém, dessa proposta enganosa? Em que medida ela se distingue da relação persuasiva, se é que se distingue? A presença desses dois termos na passagem do Elogio que trata da argumentação dirigida à consideração do peso da responsabilidade do discurso pelos atos de Helena de certa forma pretende expor o jogo intra e intersubjetivo que se realiza na linguagem. Para entendê-lo, precisamos compreender como o sofista repercute a influência de utilização desses termos.

Iniciemos pela Persuasão ( $\pi \varepsilon \iota \theta \omega ́)$. Untersteiner (2012) apresenta em Ésquilo, primeiro grande tragediógrafo, uma exemplificação da pluralidade que o termo 'persuasão' chegou a assumir. Se em Eumênides (vv.885, 970-975) a persuasão é "dotada de natureza racional [...] manifesta pelas palavras de Atena", em Agamémnon (vv. 385-387) "ao contrário, irrompe com toda a potência de um furor daimônico [...]", de maneira que a persuasão, enquanto componente do lógos, "pode ser razão e violência, força espiritual e poder daimônico" (UNTERSTEINER, 2012, p. 172). Tratar as obras de Ésquilo como um exemplo para abordar um conceito trabalhado no Elogio de Helena parece sensato porque "a persuasão definida pelos sofistas - e Górgias em particular - não está longe da Peithô de Ésquilo" (NOËL, 1989, p. 9, tradução nossa) ${ }^{7}$

Elaborando melhor esse aspecto violento da persuasão, Dinucci (2017) chegará a nomeálo como sendo um 'engano forçado'.

Uma história fictícia ou um relato de um fato a partir de uma simples opinião podem conter premissas infundadas, que ultrapassam o fato ou a ficção, e tais premissas podem envenenar a alma daquele que ouve a história ao induzir o indivíduo a um comportamento inadaptado ou inadequado diante da realidade. Nesse caso, o engano voluntário se

\footnotetext{
7 "la persuasion définie par les sophistes - et Gorgias en particulier - n’est pas si éloignée de la Peithê d'Eschyle." (NOËL, 1989, p.9).
} 
transforma em forçado (pois o indivíduo passa a crer na premissa, não a vendo mais como fictícia e falsa, mas como verdadeira), e a persuasão efetuada mostra-se maligna. (DINUCCI, 2017, p. 40).

Em outras palavras, o que Untersteiner (2012) considera, pelo recurso a Ésquilo, como traço distintivo do significado de persuasão para Górgias - uma componente violenta, embora racional, do discurso -, em Dinucci (2017) os mesmos efeitos discursivos se explicam como engano forçado, quer dizer, como condução discursiva que incita uma tomada de decisão por meio de mentiras ou premissas infundadas. Desse modo, a violência ecoada desde Ésquilo estaria, no texto georgiano, circunscrita ao julgo não da sugestão que evoca afetividade, mas do constrangimento que envenena porque aliena o ouvinte de si mesmo para aceitar a vontade (a verdade) do outro. Nesse sentido, Górgias pôde dizer: "quantos persuadiram e persuadem outros tantos a propósito de outras tantas coisas forjando um falso discurso! [...] Pois o discurso persuasivo persuade a alma, constrangendo-a tanto a crer nas coisas ditas quando a concordar com as coisas feitas" (Elogio de Helena §11; DINUCCI, 2017, p. 70-71).

Em contrapartida, o recurso à noção de engano agindo sobre a alma, conforme o $\S 8$ do Elogio de Helena, precisa ser compreendido como voluntário, de maneira a indicar um núcleo de atuação distinto do componente persuasivo e violento do discurso. Entender a soberania do lógos para Górgias é compreender, portanto, qual o poder dessa atuação não-violenta que engendra na alma o engano.

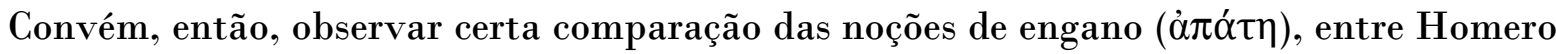
e Hesíodo, feita por Untersteiner (2012), porque elas influenciam as concepções do termo para Górgias. Para Homero, o engano [...] "transporta quem a ele está sujeito para um mundo de perfeita ilusão, no qual a realidade não se distingue mais da irrealidade" (UNTERSTEINER, 2012, p. 175). Com Hesíodo, o engano é criação das Musas. "Por isso quando elas comunicam, não é uma verdade segura e plenamente válida, trata-se de 'criação' da fantasia poética, que não exclui a "realidade"". (UNTERSTEINER, 2012, p. 176).

A partir dessas influências poéticas, é possível dizer ter se formado a noção de engano para o sofista. Vale lembrar que um dos componentes da formação retórica de Górgias foi a tragédia grega. E, conforme indica Untersteiner (2012), coube à tragédia produzir uma renovação dos mitos, porque neles estavam presentes problemas fundamentais do espírito humano. Por isso, o engano mítico e poético faz-se presente sob a consideração do engano retórico apresentado por Górgias, enquanto construção artística de uma vivência que evidencia "a capacidade da linguagem de fabricar vivências" (SALLES, 2014, p.87), ou aquilo que Cassin sintetizou na fórmula sofística: "aquele que diz, diz um dizer" (2005, p. 62). Em suma,

\footnotetext{
podemos, dessa forma, dizer que, para Górgias, a poesia, por tratar dos mitos, retrata a realidade de modo mais adequado que outras formas do discurso que tentem apontar um sentido último e transcendente para o real. E quando dizemos que a poesia retrata a realidade de modo mais adequado, não estamos dizendo que, através dela, podemos atingir um conhecimento objetivamente verdadeiro do real, mas que, por meio dela, reconhecemos o abismo entre nossa capacidade de conhecer e nossa expectativa ética e a realidade, a qual segue alheia em relação a ambas. (DINUCCI, 2017, p.38)
}

Diante dessas considerações, compreende-se que, para Górgias, o engano retórico seja certa experiência de uma vivência fictícia, portanto artística, tal como os poetas a proporcionam àqueles que assistem aos espetáculos trágicos. Está nessa aceitação voluntária de se deixar enganar o recurso georgiano para se compreender, afinal, como se fabricam em nós aprendizados. 
É preciso dizer, no entanto, que a vivência criada pelo engano se diferencia do que se costumou debater arduamente como sendo a falsidade ou mentira $(\psi \varepsilon \tilde{\cup} \delta \circ \varsigma)$ - pois essa última diz respeito à distorção, e como tal, aloca-se no âmbito da persuasão. Nesse sentido,

\begin{abstract}
quando, por exemplo, alguém escreve uma obra de ficção, apresentando-a como tal, e nós a lemos dentro desse espírito, está claro para todos que a obra não contém um relato fiel de fatos, que o desenrolar do enredo fictício não nos fornecerá qualquer dado relevante para alimentarmos nossa opinião no que se refere aos acontecimentos que envolvem ou envolveram ou envolverão coisas reais. (DINUCCI, 2017, p. 39).
\end{abstract}

Todavia, apesar da capacidade do lógos para fabricar aprendizados nos ouvintes a partir das sugestões de outros que são voluntariamente vivenciadas, nem todos os ouvintes experimentam essa capacidade do discurso. Por exemplo, quando perguntaram a Górgias " por que somente aos tessálios não enganas?', o sofista havia respondido: 'porque são muito desprovidos de sensibilidade para serem enganados por mim"". (Plutarco, De Audiendis Poetis, 15c apud UNTERSTEINER, 2012, p. 182) ${ }^{8}$. Como foi colocado, por que não seria possível enganar a todos através do lógos? Primeiro, convém observar como o engano agiu sobre a alma de Helena, o que indica, segundo Dinucci, a presença relevante da consideração acerca da opinião $(\delta o ́ \xi \alpha)$ :

\begin{abstract}
Vemos não o termo apate, mas o verbo apatao (enganar) no particípio aoristo nominativo singular referindo-se explicitamente à alma. Na verdade, o substantivo apate não aparece nem uma única vez no Helena (10), mas sim o termo próximo apatema (artifício, estratagema), referindo-se aos "enganos da opinião" (doxes apatemata) (DINUCCI, 2017, p. 28).
\end{abstract}

Com isso, o engano com o qual Górgias trata no Elogio de Helena não existe independente de qualquer situação, mas é consequência de uma relação: a relação entre a alma e a opinião, e portanto entre a aceitação voluntária e o engano. Verifica-se essa relação quando Górgias assinala: "De modo que os muitos, sobre muitas coisas, buscam com a alma a opinião conselheira" (Elogio de Helena §11; DINUCCI, 2017, p. 70). Se a alma busca uma relação de esclarecimento a partir de uma opinião, ela o fará da melhor maneira se for capaz de se deixar enganar por vivências sugeridas no discurso.

A satisfação buscada junto à opinião conselheira indica-nos as condicionantes nas quais surge a aceitação do engano: obtém-se "o prazer oriundo da empatia despertada pelos acontecimentos que envolvem os personagens" (DINUCCI, 2017, p. 40). Esse prazer decorrente da vivência sugerida por outros ilustra, para o ouvinte, os "[...] sucessos e insucessos que concernem a outras coisas e outros seres animados" iguais a ele (Elogio de Helena §9; DINUCCI, 2017 , p. 70), num tipo de assimilação capaz de "tanto o medo acalmar e a dor afastar quanto a alegria engendrar e a compaixão intensificar" (Elogio de Helena §8; DINUCCI 2017, p. 70). Górgias aqui afirma não só a capacidade de sentirmos prazer pelo tipo de experiência e aprendizado tecido ilusoriamente pelo discurso, tal como o drama em uma tragédia, mas pretende com isso avaliar, e esse é o ponto mais importante, como sendo mais sábio aquele que se deixa enganar afetivamente pelo que o lógos sugere à alma.

\footnotetext{
8 Apesar de Plutarco atribuir esse trecho a Simônides de Ceos (Cf. J. M. EDMONDS, 1924, p. 257), Untersteiner corrobora que o trecho pertencia a Górgias e foi atribuído erroneamente a Simônides por Plutarco. Independentemente de quem detenha sua autoria, é válido ressaltar o trecho porque contém um testemunho acerca de um cenário possível para a impotência do lógos, ou seja, quando os ouvintes são desprovidos de (ou talvez, se recusando a ter) sensibilidade.
} 
Tal como diz Górgias, [...] (por meio da poesia trágica) [...] aquele que é enganado é mais sábio do que o que não é enganado. Com efeito, [...] quem é enganado é mais sábio, pois quem se deixa impressionar facilmente pelo prazer das palavras não é insensível. (Plutarco, A Glória dos Atenienses 5 apud DINUCCI, 2017, p. 41).

Ao início de seu Elogio, Górgias havia indicado ser a ordem da alma a sabedoria ( $\left.\sigma 0 \varphi \varphi^{\prime} \alpha\right)$,

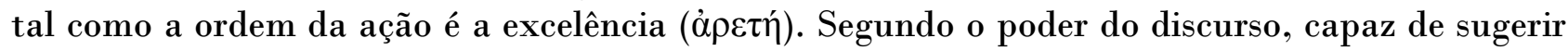
em nós o tipo de vivência afetiva e empática que torna possível a opinião sem a qual não podemos agir, aquele que se deixou enganar pelo lógos é mais sábio porque não é indiferente às experiências sugeridas em palavras por outras vivências semelhantes às suas, encontrando com isso no discurso o território em que o comum ao humano se constrói e ganha sentido. Se os tessálios não se mostraram sensíveis para o engano, eram eles apenas um caso ilustrativo dos tipos humanos que sentem a soberania do discurso não pelo prazer oferecido na ficção artística e voluntária, mas pela violência que os coagirá a nutrir na alma o veneno que os afasta dos demais em vez de os aproximar.

\section{Considerações finais}

Como vimos, a investigação sobre a soberania do lógos exigiu uma compreensão de sua natureza e de sua atuação. Quanto à natureza do discurso, compreende-se que, para Górgias, o lógos sugestiona porque comunica palavras e não coisas. Através desse poder de sugestão, fabrica no ouvinte vivências que alteram a constituição da alma, tal como medicamentos fabricam dinâmicas no corpo a fim de trazer saúde (ou doença, a depender da dose do pharmakon). Segundo a analogia, a saúde trazida pelo lógos está no aprendizado; quer dizer, a educação é a saúde da alma cujo remédio para obtê-la está no lógos. Essa maneira medicinal de dizer o lógos denuncia a compreensão técnica de Górgias sobre o seu intuito de ensinar e realizar o poder do discurso. Mas ao caracterizá-lo como um grande soberano (megas dynastes), Górgias denuncia uma implicação ético-política do discurso, que aqui só pudemos indicar a partir de uma explicitação dos traços pelos quais o sofista oferece certa educação provocada, desde as experiências fictícias vivenciadas como empatia, pela soberania não-violenta do discurso.

Isso nos levou a destacar, em Górgias, dois aspectos do discurso mencionados em seu Elogio: a persuasão e o engano. O primeiro diz respeito ao convencimento coercitivo através de mentiras e premissas infundadas, visando a ações desajustadas e à violência. A persuasão perturba e envenena a alma, porque pretende apresentar-se em lugar da verdade. $O$ segundo diz respeito à sugestão ilusória causada pela disposição voluntária e não-violenta do ouvinte para vivenciar experiências fictícias e artísticas, fundadas numa empatia que é a raiz do aprendizado e da educação. Vimos também em que medida nem todos experimentam o engano através do lógos, incapazes de ouvir dizer o dizer do discurso, por uma falta de sensibilidade que pode ser voluntária ou não. Mas os que se dispõem a essa experiência sentem, segundo Górgias, prazer decorrente da empatia e, dessa forma, aprendem através de experiências sugeridas pelo discurso e por eles vivenciadas pessoalmente, e isso os tornam mais sábios. É nesse segundo aspecto que reside a soberania do lógos. Ao contrário do que o discurso promove através da persuasão, pelo engano o ouvinte é conduzido a vivenciar situações que o abrem ao outro e ao saber, sem fechá-lo em uma mentira que pretende dizer toda a verdade. O lógos pode melhor exercer sua soberania se, ao compreendermos que tudo que há de humano assenta-se no lógos, estivermos abertos para aprender pela sugestão do que podemos ser e fazer. 


\section{Referências}

BARBOSA, Manuel José de Sousa; CASTRO, Inês Luisa de Ornellas. Górgias, testemunhos e fragmentos. Lisboa: Edições Colibri, 1993.

CASSIN, Barbara. O Efeito Sofístico: sofística, filosofia, retórica, literatura. Tradução de Ana Lúcia de Oliveira, Maria Cristina Franco Ferraz e Paulo Pinheiro. $1^{\text {a }}$ edição São Paulo: Ed. 34, 2005.

CHANTRAINE, Pierre. Dictionnaire étymologique de la langue grecque: Histoire des mots. Paris: Librairie C. Klincksieck et Cie, 1999.

DINUCCI, Aldo. Górgias de Leontinos. $1^{\mathrm{a}}$ ed. São Paulo: Oficina do Livro, 2017.//

EDMONDS, John Maxwell. Lyra Graeca; Being the remains of all the greek lyric poets from Eumelus to Timotheus excepting Pindar. London, William Heinemann; New York: G. P. Putnam's sons, 1924.

NOËL, Marie-Pierre. La persuasion et le sacré chez Gorgias. In: Bulletin de l'Association Guillaume Budé, n²2, juin 1989. pp. 139-151. Disponível em: <https://www.persee.fr/doc/bude_00045527_1989_num_1_2_1388>. Acesso em: Maio de 2021.

PERELMAN, Chaïm. Retóricas. São Paulo, Martins Fontes, 2004.

PLATÃo. Mênon. Tradução de Maura Iglésias. Rio de Janeiro; Ed. PUC-Rio, Loyola, 2001.

PLATÃO. Górgias. Tradução, ensaio introdutório e notas de Daniel R. N. Lopes. São Paulo, Perspectiva, 2011.

REBOUL, Olivier. Introdução à retórica. São Paulo: Martins Fontes, 2004.

SALLES, Lucio Lauro Barrozo Massafferri. Da palavra como phármakon. Rio de Janeiro: UFRJ, 2014.

SCHIAPPA, Edward. Did Plato coin Rethorike, The American Journal of Philology, Vol. 111, No. 4 (Winter, 1990), p. 457-470.

UNTERSTEINER, Mario. A obra dos sofistas. Editora Paulus, 2012.

Contribuição dos(as) autores(as) / Author's Contributions: Vinícius Brito Barros produziu o texto sob a orientação de Cesar de Alencar. Ambos(as) aceitaram e aprovaram a versão final do texto.

Autor(a) para correspondência / Corresponding author: Cesar Augusto Mathias de Alencar. dealencar.prof@gmail.com 